\title{
Case The Intersection of Self-Actualization, Entrepreneurship
and Transformational Leadership: A Review of
Maslow's Perspective of Eupsychian Management
}

Nura S. Akilu, Abubakar Sambo Junaidu*

Department of Business Administration, Usmanu Danfodiyo University, Sokoto, NIGERIA

*E-mail for correspondence: gidadawa56@yahoo.co.uk

Cell Phone: +2348117896795

Received: May 27, 2015;

Accepted: Jul 26, 2015;

Published: Aug 06, 2015

Source of Support: Nil

No Conflict of Interest: Declared

\begin{abstract}
An entrepreneur is someone often associated with venture creation, through what could be termed as bold undertaking; a process of treading an unfamiliar terrain characterized by overwhelming challenges known as entrepreneurship. Similarly the self actualizing individual is perceptive of possibilities and engaged in pursuits of interest that could otherwise be deemed unattainable by the multitude. These two, share commonalities akin to commitment to a purpose, meaningful enough to be sustainable and yet do not operate in isolation. They both work to inspire, motivate and organize people of shared vision in the direction of their dreams through transformational leadership. Interestingly too, there seem to be a point of convergence that characterize the seemingly varied motives, leadership style, and what could be seen as distinct set of attributions in the definitions of an entrepreneur and the self-actualizing individual. This possibility stems from the assumption that the quest for entrepreneurial success is more or less associated with the need for self actualization and forms the phenomena of interest this paper aims to explore with a view to establishing a meaningful convergence. Drawing from qualitative analysis of related literature and Abraham Maslow's works in particular, effort has been made towards this end. The findings revealed a synchronized form of the phenomena with implications that resonate around Maslow's Idea of Eupsychian Management with a recommendation for practical adoption of the concept.
\end{abstract}

Keywords: Self-actualization, Entrepreneurship, Transformational Leadership, Entrepreneurial Organization, Vision, Purpose

\section{INTRODUCTION}

Eupsychian management is Abraham Maslow's construct of what could otherwise be called enlightened management to denote management of the psychologically healthy. In his "Eupsychian Management" a journal published in 1965, the well known humanistic psychologist who also, is the proponent of the widely acknowledged hierarchy of needs theory of motivation particularly in the management literature put forward this perspective, which is considered to be more or less utopian in nature. It is an extension of his concept of self-actualization of the needs theory, which he articulated in his book titled:"motivation and personality" published in 1954.

Self actualization is a higher human need amongst the list of needs proposed by Maslow, which occupies the apex position in his gradation of needs symbolized by a hierarchical pyramid of prepotency. In his "Eupsychian management a journal", he extended this concept of self actualization to embody thirty-six set of assumptions that are descriptive of conditions necessary for this perspective of management to be feasible in the operational sense. Central to the ideas embodied in these set of assumptions is the spirit of team work in an organization of psychologically healthy people motivated and lead by a strong desire to self actualize and bonded by a deep sense of purpose and shared vision.

The in-depth analysis of Abraham Maslow's works (Motivation and personality and Eupsychian Management) with particular emphasis on the self actualization concept lead to fascinating insights, which in combination with recent research findings in the field of entrepreneurship and transformational leadership theory, inspired the development of the content of this paper. It is in this effort, aimed at making explicit the contextual associations of observable pattern of interrelationship that exist between these three constructs of self actualization, entrepreneurship and transformational leadership that a rather cohesive and complimentary nexus of interdependence becomes 
manifest. It is this manifest nexus of relationship and interdependence, which binds the three constructs that we seek to explore in the light of what we argue to be consistent with Maslow's conceptualization of Eupsychian Management. In doing this, we relied heavily on wide range of evidences that are derivable from the review of related literature. Part of the aim of this paper is to highlight the practical implication derivable from our understanding of the overall concept, in the light of the positive possibilities associated with effort directed towards making the concept operationally viable.

Following this brief introduction are the arguments, which we articulated under four sections. In the first section, a brief overview of Maslow's theory of hierarchy of needs is given, while under the second section, attempt is made to contextually equate the concept of entrepreneur with that of self actualizing individual. The third section contains an exposition of transformational leadership as byproduct of self actualization effort and the final section contains discussions of the nature of transformational leadership in entrepreneurial organizations. This is then followed by a concise conclusion of all the arguments being put forward in this paper.

\section{Maslow's Hierarchy of Needs: A Brief OVERVIEW}

In most management literature and that of organizational behavior in particular, Maslow's needs hierarchy theory has remained one of the most popular theories of motivation. Presumably, Maslow's needs hierarchy theory largely draws its wide appeal, through being able to provide both a theory of human motives in a way that classifies basic human needs in a hierarchical order and a theory of human motivation that relates these needs to general behavior (Wahba and Bridwell, 1970). The following gives a general overview of what this theory entails:

According to Maslow (1954) needs categories are structured in a hierarchy of prepotency and probability appearance. He explained that these needs follow an ascending order of prepotency and proposed the following as such: The physiological needs, the safety needs, the belongingness or love needs, the esteem needs and the need for self actualization. In order to provide the dynamic forces that linked needs to behavior, Maslow's theory of motivation describes the concepts of deprivation and gratification and utilized the former to establish dominance within his hierarchy needs. In relation to this, he opined that the chief dynamic principle animating the organization of human needs is the emergence in the healthy person, of less potent needs upon the emergence of the more potent ones. The physiological needs when unsatisfied dominate the organism, pushing all capacities to their service and organizing these capacities so that they may be more efficient in this service. In relation to this, Whittengten and Evens (2005) explain that the deprivation or dissatisfaction of a need of high potency will lead to the domination of this need over the organism's personality, and that this dynamic cycle over time of deprivation-domination-gratification-activation continues until the physiological, safety, social and esteem needs have all been gratified and self actualizing need has been activated.

Maslow (1965) modified the gratification-activation ideas by proposing that in a growth-motivated self actualizing individual, gratification of the self actualizing needs causes an increase in its importance rather than decrease. Maslow also pointed out that the long deprivation of a given need may create a fixation (A state of mind involving obsession with a particular person idea or thing). He added that higher needs may emerge not after gratification, but after deprivation, renunciation or suppression of lower needs (Bogdan, 2008)

However Maslow's theory has its own share of criticism. There are discussions centered around cultural relativity and universalism, the directionality implied by the model of gratification and deprivation, the validity of the original categories of needs and the lack of operational convenience that generally characterize the model . Existing research refutes the existence of the original need categories and questions the directional hierarchy that Maslow proposed, but it supports the concept of self actualization, the existence of lower and higher needs and the concept of gratification-deprivation as motivators of human behavior (Reid, 2008).

\section{THE Typical ENTREPRENEUR Versus MasLOW'S SELF ACTUALIZING INDIVIDUAL}

The topic of motivation has long been a focal interest to organizational researchers and their investigations have resulted in the development of sophisticated frame works for understanding motivation in entrepreneurial settings. Such investigations have revealed the relational importance of individual entrepreneur and the environment, particularly within the context of the motives that characterize entrepreneurial behavior (Jarillo and Stevenson, 1990). This may imply that relevant to the understanding of entrepreneurial behavior is the exposition of the underlying motive that seem pivotal to the entrepreneurial effort. This could as well help define the entrepreneur, on the basis of the behavioral underpinnings that derive from motivational inclinations. Having previously established from the foregoing, that Maslow (1954) in his theory of human motivation relates the concept of needs to general behavior, it is logical to assume, that self actualizing need, which is expressed in behaviors consistent with the exploitation of talents, capacities or potentials (Maslow, 1965), is traceable in most entrepreneurs. This becomes evident if one considers the general tendency of entrepreneurs, towards "broadening and building" efforts aimed at expanding their repertoires in the direction of their inherent potentialities, (Fredrickson, 2001). In describing the self 
actualizing individuals, Maslow explained as quoted below:

“........Self actualizing people have some mission in life, some task to fulfill, some problem outside themselves which enlist much of their energies...they work within a framework of values that are broad and not petty, universal and not local and in terms of a century rather than the moment...they have autonomy which is self decision, self government, being an active, responsible, self disciplined, deciding agent rather than a pawn, or helplessly determined by others, being strong rather than weak. They make up their own minds, come to their own decisions, are self starters are responsible for themselves and their own destinies.....self actualizing individuals are generally fixed on ends rather than on means, and means are quite definitely subordinated to these ends.......thus it comes about that doubt, tentativeness, uncertainty, with the consequent necessity for abeyance of decision, which is for most a torture, can be for some, a pleasantly stimulating challenge, a high spot in life rather than the low.....they are generally unthreatened and unfrightened by the unknown and even more attracted to it than the known....."

(Maslow, 1965)

In order to further clarify the conceptual foundation of the argument presented in this paper, a conscientious attempt would be made, with a view to dissecting the above quotation in a way that establishes an associative tendency, with respect to Maslow's conceptualization of the self actualization individual(as derivative of what the content of the above statement implies) as well as how it relates to certain attributions commonly used, in the description of a typical entrepreneur, from the view point of psychological context of the concept of entrepreneurship. The psychological perspective in entrepreneurship has mainly concentrated on finding stable characteristics. This perspective apparently attempt to link various characteristics with the state or being of entrepreneurs, while also attempting to use certain characteristics to define behavior that seem consistent with most entrepreneurs with respect to their performances and in relation to the kind of business they run (Delmer, 1996). Among the most popular characteristics to be found in extent literature are: Need for achievement, internal locust of control, risk taking propensity, tolerance for ambiguity, optimism and need for autonomy (Delmer, 1996). Going by the opinion of Venkataram (1997) that entrepreneurship involves the nexus of the presence of lucrative opportunities and the presence of enterprising individual, what is intended in the present work is specific inclination towards the latter rather than the former. But this is on the basis of the contextual convenience this inclination offers for our purpose and not on the basis of any perceived or actual contradiction that seem attributable to other views not consistent with ours.

This offers a befitting framework therefore for our subject matter, which is the identification of Maslow's claims with respect to the features or the characteristics of self actualizing individuals with that of a typical entrepreneur. We do hope to eventually establish this, in the light of the characteristic similarity that seem implicit in his quoted statement above about self actualizing individuals, relative to the six common characteristics of entrepreneurs also previously identified in the foregoing. According to Maslow (1965), self-actualizing individuals work within a framework of values. Which means their behavior emanates from values (Verplankenand Hollad, 2002) and values induce valence on possible actions (Feather, 1995). AsMoriano, Palaci and Morales (2007) put it; values positively predict entrepreneurial intention and therefore significant relationship between individual values and entrepreneurial intention is to be expected, (Linan and Moriano, 2007). Implicit also in Maslow's statement, is the long term perspective of self-actualizingindividuals. They operate within a framework of values that are broad and not petty, universal and not local and in terms of a century rather than the moment (Maslow, 1965) and this makes the values relatively enduring overtime. This focus on long term is expressed by Timmons (2000) as one of the features that increases the chances of start-ups, survival and success of entrepreneurs who hold strongly to their goals.

Self actualizing people according to Maslow (1965) have some mission in life, some task to fulfill, some problem outside themselves which enlist much of their energies. Implicit in this statement is the need for achievement and entrepreneurs are individuals that have a high need for achievement and that characteristic makes them especially suitable to create ventures McClelland, (1961).

Self-actualizing individuals make up their own minds, come to their own decisions, are self starters are responsible for themselves and their own destinies... (Maslow,1965). This is descriptive of individuals who believe that the achievement of their goal is dependent on their behavior or characteristics, they therefore believe in internal control (Delmer, 1996). This quality is referred to as locust of control. According to Koh (1996) entrepreneurs have been variously characterized as possessing internal locust of control.

Risk taking propensity is closely associated with tolerance for ambiguity and entrepreneurs have somewhat tolerance of that sort (Master and Meir, 1988). This characteristic is also implied in Maslow's description of the self-actualizing individual. He opined that doubt, tentativeness, uncertainty, with the consequent necessity for abeyance of decision, which is for most a torture, can be for some (Self-actualizing individuals), a pleasantly stimulating challenge, a high spot in life rather than the low(Maslow, 1965).

Entrepreneurs have been found to have a high need for autonomy, they value individualism and freedom (Sexton and Bowman, 1985). This also coincides with Maslow's description of self actualizing individuals. According to him, they have autonomy which is self decision, self government, being an active, responsible, self disciplined, 
deciding agent rather than a pawn, or helplessly determined by others, being strong rather than weak (Maslow, 1965)

Self actualizing individuals are generally unthreatened and unfrightened by the unknown and even more attracted to it, (Maslow, 1965). The tendency for them to be hopeful and confident about future eventualities therefore becomes obvious, and that makes them thrive on optimism which is a state of mind that relates to expectancy of success and majority of entrepreneurs were found overoptimistic about their success rate, (Eggers and Churchill, 1996).

From the foregoing, it becomes clear that implicit in the description of self-actualizing individuals given by Maslow, are characteristics attributable to a typical entrepreneur as deducible from extent literature. This then implies that to tend towards entrepreneurial effort could as well mean to thread on the path of selfactualization. This is not to say however that all entrepreneurs are self-actualizers. Rather what is implied is that; inherent in the character of most entrepreneurs who are known to have distinguished themselves through their value adding capacity and practical contributions to humanity, are attributions that are descriptive self-actualizing individuals. Hence successful entrepreneurial ventures are outcomes of efforts made by self-actualizing individuals in their quest for the exploitation of their full potentials.

\section{TRANSFORMATIONAL LEADERSHIP AS BYPRODUCT OF SElF-Actualization EFForTS OF ENTREPRENEURS}

Self-fulfillment can be translated into Self-Actualization and since entrepreneurial behaviors are used as means to achieve wealth or self-fulfillment they could be seen as efforts geared towards self-actualization (Baumeister, 1987). This is expressed in the need to use one's competence, abilities, strength or in aword; potentials through giving, helping, serving and making contributions to make the world a better place (Perret and Mainali, 2012). Entrepreneurs achieve these by getting self employed, through the acts of starting, organizing, managing and assuming responsibility for a business (Segal, Borgia and Schoenfeld, 2005). The sense of fulfillment derived there from, is what most entrepreneurs search for when starting a company and this puts them at the very heart of the created venture thereby playing a major role in shaping their companies' direction and outcomes as organizational leaders (Markman, Baron and Balkin, 2003). It is however important to note that while certain entrepreneurs seek self-actualization through the starting and running of their business some do not (Carland and Carland, 1997). Our emphasis is however on the former rather than the latter, hence our concern with the leadership of entrepreneurial organizations.

Entrepreneurial organization has a culture that facilitates entrepreneurial activity and puts together teams of people with the right combination of entrepreneurial characteristics. It is therefore characterized by four distinct factors: Leadership, organizational culture, the teams' composition and dynamics, as well as employee profile (Metaprofiling 1td, 2013). Such characteristics derive from a meaningful mission and long term plan of action, with a grand vision that serve as a constant point of reference (Metaprofiling ltd 2013). For a fairly good (entrepreneurial) organization, work tends to improve the people and then tends to improve the industry, which in turn tends to help the people involved and so it goes (Maslow, 1965). People who run such organizations are therefore motivated by the need for self actualization.

Self actualizing individuals are metamotivated by metaneeds which is expressed in their devotion and dedication to and identification with some great or important job. For them duty cannot be contrasted with pleasure, nor work with play and the person doing his duty and being virtues is simultaneously seeking the pleasure of being happy (Maslow, 1965). Berkowitz (1969) asserts; that Self-actualization is based more on the wishes of what a man is supposed to be, with respect to his or her own standard, rather than what he or she currently is. And since entrepreneurship contributes to building the path toward the achievement of that which is sought for (Gilad and Levine, 1986), transformational leadership (which starts with the transformation of self-actualizing individuals) becomes a byproduct of self-actualization efforts of entrepreneurs who tread the path of entrepreneurship, when they set up entrepreneurial organizations.

\section{TRANSFORMATIONAL LEADERSHIP ENTREPRENEURIAL ORGANIZATION}

Central to the concept of entrepreneurial organization is the idea of organization's entrepreneurial attitude. This attitude is expressed as a combination of cultural values bond by leadership, vision and objective, incorporated and lived by people in the organization (Rodrigues, Almeida and Riccardi 2003). These people or individuals have a relationship and a shared purpose aimed at meeting the needs of one or more persons or stake holders (Covey, 2004). Both management and leadership are vital in running an organization and either one without the other is insufficient. This is so because the core of managerial role in organizations is centered on strategy, structure and systems (Barlett and Ghoshal I989) in that, these are "things" to be managed and controlled (Covey, 2004). But since the highest challenge inside organizations, (especially entrepreneurial organizations) is having to set them up and run them in a way that enables each person to inwardly sense his or her innate worth and potential for greatness and to contribute his or her unique talents and passion, leadership becomes indispensible. This is because "things" don't have the freedom to choose (from alternative courses of action) only people do, and this necessitates the need for them to be lead (Covey, 2004) in the right direction. 
A meaningful mission and long term plan of action is one of the key tasks of leadership in any organization, but in the entrepreneurial organizations, where people are empowered to a much greater extent, vision becomes central (Metprofiling ltd, 2013) . This is because it creates a common purpose that helps pull people in a desired direction while increasing performance and commitment (Kirkpatrick and lock 1996). This type of leadership which is transformational in nature requires leaders who are capable of offering a purpose that transcends short term goals and focuses on higher order intrinsic needs (Burns, 1978). Transformational leadership which is described as a process by which leaders and followers raise one another to higher levels of morality, would fit into the higher levels of Maslow's hierarchy of needs as it requires a high level of authenticity, self esteem and self actualization (Burns, 1978)

According to Maslow (1965) People have a range of needs and the extent to which they will perform effectively in the work place will be affected by the extent to which these needs are satisfied. Transformational leadership fits into these higher levels since it requires a high level of self esteem and self actualization to successfully be an authentic leader. Covey (2004) opined that the goal of transformational leadership is to transform people and organizations in a literal sense. To change them in mind and heart, enlarge vision, insight and understanding. To help them clarify purposes, make behavior congruent with belief, principles or values and bring about change that is permanent, self perpetuating and momentum building.

Entrepreneurs as self actualizing individuals are engaged in creating activities fueled by their own passions, desires and natural inclinations. It is an obvious fact however, that any attempt to creating anything, would be confronted with overwhelming challenges from all ramifications. It involves a tedious process through which individual transformation takes place, and this essentially precedes the desire to transform others. Going by this, it thus can be expected, that entrepreneurs are themselves transformed or are transforming in the process of entrepreneurship. Since the major premise of transformational leadership theory is the leader's ability to motivate the follower to accomplish more than what the follower planned to accomplish (Krishnan, 2005) entrepreneurs as organizational leaders through the process of entrepreneurship are likely to have their employees transformed into the image of themselves as self actualizing individuals. This would ensure success due to shared vision and this is even more likely, since according to Rodrigues, Almeida and Riccardi (2003) entrepreneurial organization (in which this kind of relationship predominates)is in fact a reflection of the quality of its leadership. This is a kind of leadership, which according to Burns (1978) is considered true kind of leadership. According to him, it creates change and achieves goals within the environment and also has the capacity to change the people involved, in the necessary actions for the better. He concludes that both followers and leaders eventually become inevitably ennobled.

\section{EUPSYCHIAN MANAGEMENT: MASLOW'S Perspective of Transformational Leadership OF SELF ACTUALIZING INDIVIDUALS}

Maslow used the term "Eupsychian" to denote development towards psychological health. He described eupsychian management as a form of patriotism and love of a country applied to the industrial and to the work situation (Maslow, 1965). He interchangeably used the expression "Enlightened management" in explaining the same concept. In the following long quotation Maslow gives a vivid illustration of what he meant by Eupsychian management:

.....I think a very effective way of communicating the point and ultimate goals of eupsychian management can be seen in this way: If a group of a hundred men all become partners and invested their pooled savings in an enterprise and they each had one vote, so that they will consider themselves both workers and bosses all of them, the relationship of each to the enterprise and to each other would be very different from the classical model of boss hiring a hand, an impersonal worker. The example is similar also to the situation of a group of patriotic people at war against a common outside enemy. In both of these cases anybody will do anything which has to be done.........In a brotherhood situation of this sort everybody is transformed into a partner rather than into an employee. He tends to think like a partner and act like partner. He tends to take upon his own shoulders all the responsibility of the whole enterprise. $\mathrm{He}$ tends voluntarily and automatically to assume responsibility for any of the various functions of an enterprise which any emergency might call for. Partnership is the same thing as synergy which is the same thing as recognizing that the interest of the other and one's own interest merge and pool and unite instead of remaining separate or opposed or mentally exclusive...............It is easy for passive people or for shrewd people to mimic any behavior or to put in any act which might be necessary for them to keep their job or to get ahead in any particular situation. They may act the way management wants them to, but their souls might be totally unchanged........The man who truly is influenced by enlighten management should become a better husband and a better father as well as a better citizen in general.

(Maslow, 1965)

This quotation is self explanatory, but also deducible there from, are certain implicit indicators of synergistic organizational transformation with an accompanied positive impact of heartfelt commitment towards the attainment of set objectives on the part of organizational members. This could as well be considered consequential, subject to operationally being put into use, the theoretically prescribed eupsychian management concept of Maslow. Consider also the following quotation: 
".....The path of personal transformation is primarily a process of becoming aware of facing up to and taking responsibility for one's thoughts and feelings and actions, and then expanding this self-realization by communicating with others.......Self-actualization individuals are motivated by growth. They are also aware of their primary goals in life and are devoted to fulfilling them, both for their own benefit and as service to others...........Eupsychian economics must assume as a prerequisite synergistic institutions set up in such a way that what benefits one benefits all..... suppose we will have to work out here a little bit of the psychodynamics of team work, of identification with the team or the organization.....everyone can enjoy good team work, friendship, good spirit, good group homonomy, good belongingness and group love." (Maslow, 1965)

We shall highlight and explain further the content of these quotations in the light of what Covey (2004) called the four roles of leadership namely: Modeling, Path finding, Aligning and Empowering.

Aligning employee behavior in order that it becomes consistent with the attainment of organizational objectives is a concern that is central to organizational leadership and management. This concern normally translates into efforts towards stimulating strategically aligned behavior which is often thought to be influenced by a number of factors. For instance openness, participation and supportiveness which increase employees sense of belonging to the organization through the giving of the feeling, that management regards them as true members of the organization (Smids, Pruyn and Riel, 2001), could be very supportive of such behavior (Riel, Berens and Dijkstra, 2009). This is in essence, what Maslow points at, when he equates partnership with synergy in an organizational situation, where everybody is transformed into a partner rather than employee. This according to him, makes the interest of the other and one's to merge, pool and unite instead of being separate, opposed or mutually exclusive, in which case everybody has to do anything that has to be done (Maslow, 1965). This is essentially what is meant by organizational commitment, and in entrepreneurial organizations commitment echoes the capacity to ensure venture success (Erickson, 2000)

Empowering, enthrones self-control, self-management and self organizing. It is the natural result of both personal and organizational trustworthiness, which enables people to identify and unleash their human potential (Covey, 2004). In Maslow's terms, this takes place when an employee is made to think like a partner and act like a partner. In which case he or she becomes empowered, to take upon his or her own shoulders the responsibility of the whole enterprise, by voluntarily and automatically assuming responsibility for any of the various functions of an enterprise, which any emergency might call for (Maslow, 1965). This is in essence transformational and it leads to higher level of empowerment and thus requires transformational leadership, which could be very useful in entrepreneurial organization (Kark, Shamir and Chen, 2003).
The Aligning and Empowering roles according to Covey (2004) are aimed at execution of the leadership function in organizations, but what precede them are Modeling and path finding roles which provide focus prior to execution. He stressed this in consideration of the assumption that personal development (Which is the function of focus) precedes the building of trusting relationships, and trusting relationships are absolute prerequisite to developing an organization characterized by teamwork, cooperation and contribution to the wider community.

Modeling character and competence lays the foundation for trust in every relationship and organization, yet being a model involves finding one's own voice first and then choosing the attitude of initiative or taking initiative to expand one's influence in every opportunity (covey, 2004). Attempting to find one's own voice, implicitly demands however, that one undergoes the process of transformation and the path of personal transformation according to Maslow (1965), is primarily a process of becoming aware of, facing up to and taking responsibility for one's thoughts, feelings and action. Expanding this selfrealization would mean increased influence which as Maslow adds, takes the form of communicating with others. But Modeling is not just the work of an individual; it takes the work of a team, and Maslow speaks of Psychodynamics of team work, of identification with the team or the organization. He proposed, that eupsychian economics must assume as a prerequisite, synergic institutions set up in such a way that what benefits one benefit all (Maslow, 1965). In such a team of people that builds on each individual's strength and organizes to make individual weakness irrelevant true organizational power is unleashed (Covey, 2004).

Path finding involves creating with others a common vision about high priorities and the values by which they are achieved (Covey, 2004). By communicating their primary goals with others, self actualizing individuals who are motivated by continual growth make themselves and others devoted to fulfilling these goals both for their own benefit and for the purpose of being of service to others (Maslow, 1965). Vision on a personal scale, according to Covey (2004), translates into path finding in an organizational setting and the challenge is associated with the leader's role of having to create a shared view of what is important and what matters most. In entrepreneurial organizations that thrives on uncertainty path finding would require coming together of the art of possibility with the art of probability in order to understand the anatomy of the road that paves the way for extraordinary accomplishment (Richardson, 2007)

\section{CONCLUSION}

The need for self actualization as revealed by the foregoing stands pivotal to the developmental imperative, which precedes the acquisition of entrepreneurial disposition. Such acquired disposition is attributable to the self actualizing individual in much the same way it is ascribable to a typical entrepreneur. The possibility of this 
happening derives its legitimacy from what has so far been previously established, as characteristic similarities that define the dual constructs of the entrepreneur and the self-actualizing individual. Connected to this, is the inevitability of the transformational tendency that characterizes the associated quest to be self actualized, by individuals that share such entrepreneurial disposition. What could be added with respect to this with a considerable level of certainty is that; personal transformation precedes organizational interdependence. And the nature of this personal transformation is such that it inspires the occurrence of same manifestation amongst group of people with a shared vision.

The tendency of multiple individual transformation of a group of people unified by a sense of shared purpose is supported by a genuine eupsychian team spirit of a sort deemed healthy, for an entrepreneurial venture. Such ventures are identified by the relentless efforts they exert towards the exploration and exploitation of ideas necessary, for continuous conversion of business opportunities into successful value adding business ventures.

Going by this, it thus can be concluded that Maslow's eupsychian management could as well be equated with the concept of transformational leadership and both are descriptive of four identified roles of organizational leadership as proposed by Covey (2004), namely; Modeling, Pathfinding, Aligning and empowering. Most importantly, a principled commitment to carrying out these roles effectively by a transformational leader or eupsychian manager in an entrepreneurial organization, would yield organizational synergy of the differential contributions of teaming members, in their collective efforts towards successful attainment of set objectives. This makes the operational use of the conceptualization of this phenomenon highly recommendable especially in organizational situations characterized by high level of low trust, disempowerment, misalignment and total lack of meaningful vision.

\section{REFERENCES}

Abraham H. Maslow (1965). Homewood, Illinois Richard D. Irwin, Inc and Dorsey press

Abraham H.Maslow (1954). Motivation Personality. Harper \&Row, Publishers, Inc Eusychian Management.

Anca, B.(2008).Motivational Issues in Knowledge Work, Revista Informatica Economică, nr. 4(48).

Bartlett, C. A. \& Ghoshal, S. (1989). Managing Across Borders: The Transnational Solution, 1st edition. Boston, MA: Harvard Business School Press.

Baumeister, F.R (1987). How the Self Became a Problem: A Psychological Review of Historical Research. Journal of Personality and Social Psychology, 52(I): 163-176.

Berkowitz, L. (1969). Social motivation. In G. Lindzey and E. Aronson (eds.), Handbook of Social psychology, (2nd ed.), Vol. 3. Reading, MA: Addison-Wesley.

Burns, J. M. (1978). Leadership. New York: Harper \& Row.

Covey Stephen R. (2004). The $8^{\text {th }}$ Habit from effectiveness to greatness: free press 2004 ISBN 0-743287932
David Gay-Perret \& Anup Mainali (2012). Master's thesis within Business Administration Leona Achtenhagen Jönköping May.

Delmar, F. (1996). Entrepreneurial behavior and business performance. Stockholm School of Economics, Stockholm

Eggers, J. H.; Leahy, K. T. \& Churchill, N. C. (1996). Leadership, management, and culture in high-performance entrepreneurial companies. In Frontiers of Entrepreneurship research, Babson: Babson- College.

Erikson, T. (2002). "Entrepreneurial capital: The emerging venture's most important asset and competitive advantage". Journal of Business Venturing.17: 275-290.

Feather, N. T. (1995).Values, valences. and choice: The influence of values on the perceived attractiveness and choice of alternatives. Journal of Personality and Social Psychology, 68: 135-1151.

Fredrickson, B.L. (2001). The role of positive emotions in positive psychology: the broaden-and-build theory of positive emotions. American Psychologist, 56: 218-226.

Gilad B, Levine P (1986). A Behavioral Model of Entrepreneurial Supply, J. Small Bus. Manag., 4: 45-53.

James W. Carland and Jo Ann C. Carland James W. (Trey) Carland, III (2013). A Model Of Entrepreneurship: The Process Of Venture Creation, Entrepreneurial organization: What is it and why it matters Meta profiling Ltd.

Kark, R.; Shamir, B. \& Chen, G. (2003). The two faces of transformational leadership: Empowerment and Dependency. Journal of Applied Psychology, 88(2): 246-255

Kirkpatrick, S.A. \& Locke, E.A. (1996). Direct and indirect effects of three core charismatic leadership components on performance and attitudes, Journal of Applied Psychology, 81(1): 36-51.

Koh, H.C. (1996), "Testing hypotheses of entrepreneurial characteristics: A study of Hong Kong MBAstudents", Journal of Managerial Psychology, 11:12-25.

Krishnan, V. R. (2005). Transformational leadership and outcomes: Role of relationship duration. Leadership $\mathcal{E}$ Organization Journal, 26(5/6): 442-457.

Liñán, F. \&Moriano, J. A. (2007).Entrepreneurial Intentions. In J. A. Moriano \& M. Gorgievski (Eds.), Psychology of Entrepreneurship: Research and Education (pp. 39-56). Madrid: UNED

Locke, E. A. (2000). The Prime Movers. New York: Amacom

Mahmoud A. Wahba and Lawrence G. Bridwell (1976). Organizational Behavior and Human Performance, 15, 212240. Maslow Reconsidered: A Review of Research on the Need Hierarchy Theory

Markman, G. D.; Baron, R. A. \& Balkin, D. B. (2001). Adversityquotient: Perceived perseverance and new venture formation. Paper presented at the meeting of the Academy of Management, Washington, DC.

Maslow's Theory of Motivation and Hierarchy of Human Needs: A Critical Analysis Allison Ruby Reid-Cunningham, MSW School of Social Welfare, University of California - Berkeley Prepared under the supervision of Dr. William McKinley Runyan, School of Social Welfare $\mathrm{PhD}$ Qualifying Examination, December 3, 2008.

Masters, R. \& R. Meier (1988). "Sex Differences and Risk Taking Propensity of Entrepreneurs". Journal of Small Business Management, 26 (1): 31-35.

McClelland, D.C. (1961). The Achieving Society. Princeton: Van Nostrand.

Mike Richardson (2007). Path-Finding: The Art of Possibility $\mathcal{E}$ Probability, Sherpa Alliance. 
Moriano, J. A.; Palací, F. J. \& Morales, J. F. (2007). The Psychosocial Profile of the University Entrepreneur. Psychology in Spain, 11:72-84

Riel V.; C. B. M.; Berens, G. \& Dijkstra, M. (2009). Stimulating Van strategically aligned behaviour among employees. Journal of Management Studies, 46(7): 1197-1226.

Rodrigues, Leonelcezar; Almeida, Martinhoisnardribeiro De \&Riccardi, Riccardo. (2003). Entrepreneurial Organization: The RightIngredient for growth strategy. In: International Conference Global Business and Technology Association (GBATA), 2003, Budapest. Proceedings do International Conference Global Business and Technology Association - GBATA. Global Business and Technology Association, 1: 1134-1143.

Segal, G., D. Borgia, \& J. Schoenfeld. (2005). The motivation to become an entrepreneur. International Journal of Entrepreneurial Behavior and Research, 11 (1): 42-57.

Sexton, D.L. \& N.B. Bowman (1984). Personality inventory for potential entrepreneurs: Evaluation of a modified JPI/PRF/E test instrument, Paper presented at the Babson Entre. Conf., Wellesley, MA: Babson College.

Sexton, D.L. \& N.B. Bowman (1985) The entrepreneur: A capable executive and more, Journal of Business Venturing, 1: 129-140.
Smids, A.; Pruyn, A. \& Van Riel, C.B.M. (2001).The impact of employee communication and perceived external prestige on organizational identification. Academy of Management Journal, 44(5): 1051-1062. DOI: 10.2307/3069448

Stevenson, H.H. \& Jarillo, J.C. (1990). “A Paradigm of Entrepreneurship: Entrepreneurial Management",Strategic Management Journal, 11:17-27.

Timmons, J. A. (2000). New Venture Creation: Entrepreneurship 2000 ( $5^{\text {th }}$ ed.). Homewood, IL: Irwin.

Venkataraman, S. (1997). The distinctive domain of entrepreneurship research: An editor's perspective. In J. Katz \& R. Brockhaus (Eds.), Advances in entrepreneurship, firm emergence, and growth, 3:119-138. Greenwich, CT:

Verplanken, B., \& Holland, R. W. (2002). Motivated decision making: Effects of activation and selfcentralityof values on choices and behavior. Journal of Personality and Social Psychology, 82:434-447.

Whittington, J. L.\& Evans, B. (2005). General issues in management: the enduring impact of great ideas. Problems and Perspectives in Management, 2, 114-122.

$--0--$ 